\title{
Exploring barriers to social inclusion for disabled people: perspectives from the performing arts
}

\author{
Ayse Collins $^{1}$ (D), Ruth Rentschler ${ }^{2}$ (D), Karen Williams ${ }^{3}$ (D) and Fara Azmat ${ }^{4}$ \\ ${ }^{1}$ Faculty of Applied Sciences, Bilkent University, Ankara, Turkey, ${ }^{2}$ UniSA Business, University of South Australia, Adelaide, \\ Australia, ${ }^{3}$ UniSA Online, University of South Australia, Adelaide, Australia and ${ }^{4}$ Department of Management, Deakin \\ University, Melbourne, Australia
}

Author for correspondence: Ayse Collins, E-mail: collins@bilkent.edu.tr

(Received 25 January 2021; revised 16 August 2021; accepted 5 September 2021)

\begin{abstract}
Although the potential of arts to promote social inclusion is recognised, barriers to social inclusion for disabled people in the arts is under-researched. Based on 34 semi-structured interviews with disabled people and those without disability from four arts organisations in Australia, the paper identifies barriers for social inclusion for disabled people within performing arts across four dimensions: access; participation; representation and empowerment. Findings highlight barriers are societal, being created with little awareness of needs of disabled people, supporting the social model of disability. Findings have implications beyond social inclusion of disabled people within the arts, demonstrating how the arts can empower disabled people and enable them to access, participate and represent themselves and have a voice. Our framework conceptualises these four barriers for social inclusion for disabled people for management to change.
\end{abstract}

Key words: Barriers; disability; performing arts; social inclusion; social model of disability

\section{Introduction}

Social inclusion of disabled people has emerged as a major management and policy issue in Australia (Gooding, Anderson, \& McVilly, 2017). Currently, one in five Australians are disabled (4.2 million). Although social inclusion is not limited to income/poverty, Australia is the lowest-ranked Organisation for Economic Co-operation and Development (OECD) country for relative income of disabled people with $45 \%$ of them near or below the poverty line (OECD average: 22\%) (Addis, Michaux, \& McCutchan, 2018). With unemployment higher, poverty more pronounced and poor health and crime higher for disabled people, there is an urgent economic and social need for social inclusion of disabled people in society (Addis, Michaux, \& McCutchan, 2018; Thomas, Gray, McGinty, \& Ebringer, 2011). Although national disability policy in Australia supports social inclusion, with some government departments undertaking studies in partnership with arts organisations (DADAA Inc., 2014), it is surprising how little academic and sectoral attention disability in the arts has received. As a 'means of expression and development' and with an 'approach to creative activity that connects artists and local communities' (Barraket, 2005, p. 3), evidence suggests that arts - encompassing visual, performing and literary arts, ranging from elite to community arts - leads towards social inclusion of individuals (Azmat, Fujimoto, \& Rentschler, 2015; Barraket, 2005). Individual benefits derived from the arts can lead to greater self-esteem, while at the community level the arts can contribute to neighbourhood renewal, create or strengthen communities, develop social capital and promote social inclusion by addressing social challenges, such as health, crime, employment and education in deprived communities (Azmat, Fujimoto, \& Rentschler, 2015). Furthermore, the arts 'comfort in times of trouble', heal, inspire community participation and foster a compassionate society 
(Chew, 2009, p. 9). However, social inclusion and its subsequent benefits are beset by barriers which may be unequally distributed and/or unattainable for some disabled people, a topic which has received limited academic attention. Management implications include changes in policy and praxis that entail taking an integrated approach to disabled people focusing on multiple levels (Syed \& Kramar, 2009), as described later in this paper. Within this context, this paper aims to examine barriers to social inclusion of disabled people in the performing arts. For the purpose of the paper, we define disabled people as those with physical, cognitive or intellectual disability.

Although management scholars have examined social inclusion in relation to Indigenous artists (Congreve \& Burgess, 2017) and disabled people in community organisations (Fujimoto, Rentschler, Le, Edwards, \& Härtel, 2014), the management perspective has received less attention with respect to disabled people in the arts. Accordingly, this paper fills this gap in the management literature by examining barriers that disabled people face in relation to their social inclusion in the arts, with regards to four dimensions: access (Gidley, Hampson, \& Wheeler, 2010; Kawashima, 2006; Kusayama, 2005), participation (Evans, Bellon, \& Matthews, 2017; Gidley, Hampson, \& Wheeler, 2010; Kawashima, 2006; Putnam, 2000), representation (Kawashima, 2006; Lindelof, 2015) and empowerment (Evans, Bellon, \& Matthews, 2017; Gidley, Hampson, \& Wheeler, 2010; Themudo, 2009; vom Lehn, 2010). We answer the following research question: What are the barriers to social inclusion for disabled people in the arts?

We use a qualitative study of semi-structured interviews to examine the question using the lens of the social model of disability. We interview disabled people who are actively involved in the performing arts, namely disabled audiences, carers, disabled artists in performing arts and people working in performing arts organisations such as artists and administrators as well as advocates, executives and board directors. Such diversity in participants enabled us to examine challenges in social inclusion in the performing arts.

The study contributes towards expanding knowledge about barriers to social inclusion of disabled people in the performing arts by bringing together and analysing four dimensions of social inclusion that have not previously been examined holistically. Furthermore, using the voices of disabled people and other stakeholders, it develops a framework for management to better understand and conceptualise inclusion issues facing disabled people and identify key barriers to their social inclusion, which is timely given the under-researched nature of the topic. The framework (see Figure 1) thus provides a starting point for change leading to workplaces becoming better suited to maximising the inclusion of disabled people and could be applied for inclusion of people from other disadvantaged backgrounds as well as migrants or refugees. The framework also contributes to facilitating academic discussion about social inclusion/exclusion of disabled people and other disadvantaged members in workplaces. Although the framework is developed based on a study in the Australian context, its findings could be generalised to other nations seeking to understand barriers to social inclusion for disabled people as a means of seeking to overcome them.

The rest of this paper is structured in the following way. We start by discussing the social model of disability to provide the theoretical underpinning of our study. Next, we provide insights into different interpretations of social inclusion and its four dimensions (access, participation, representation and empowerment) followed by an examination of how arts can facilitate social inclusion. This is followed by a discussion of our methodology, the findings, the empirical model and the theoretical and managerial implications of the study.

\section{Literature review}

\section{Social model of disability}

To further understandings of barriers faced by disabled people within the performing arts, this paper draws upon the social model of disability - a model that focuses on societal structures 


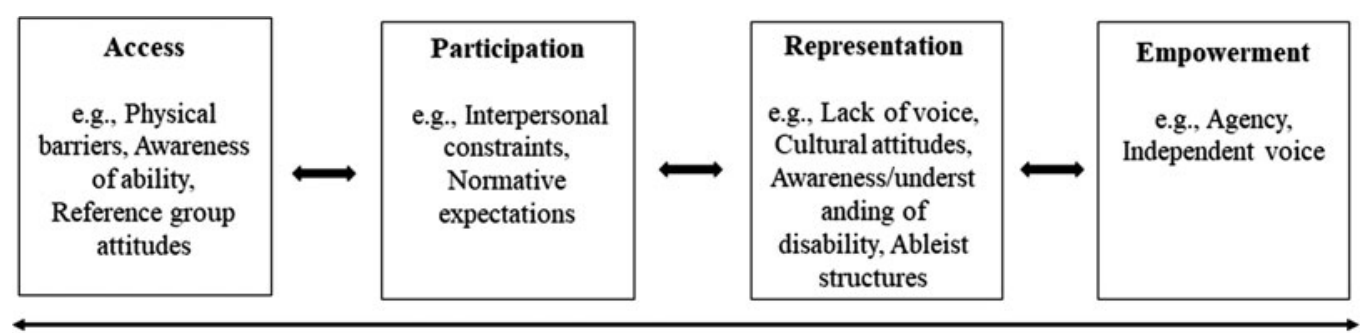

Fig. 1. Access, participation, representation and empowerment (APRE) framework of barriers to social inclusion.

rather than individual impairment (Woods, 2017, p. 1094). The social model recognises/makes the crucial difference between impairment and disability (Oliver, 1990). Within this model, impairment is defined 'in relation to a species norm in terms of functional ability' (Chapman, 2020, p. 218) or 'loss' in some ability that is assumed to be common to humans with impairments themselves' (Rosqvist, Chown, \& Stenning, 2020, p. 5). It considers disability to be societal failure, failing to accommodate and accept impaired individuals (Oliver, 1990). People are disabled by ableist structures, both physical and attitudinal (Rosqvist, Chown, \& Stenning, 2020, p. 5). Rather than an individual issue, the social model emphasises 'material factors, social relations and power structures that exclude people with a disability' (Verhaeghe, Van der Bracht, \& Van de Putte, 2016, p. 234). As argued by Oliver (1990, p. 33), this includes:

all the things that impose restrictions on disabled people; ranging from individual prejudice to institutional discrimination, from inaccessible public buildings to unusable transport systems, from segregated education to excluding work arrangements.

The social model, hence, argues for the removal of these barriers and has been accompanied by a social movement designed to politically address the social exclusion of disabled people (Verhaeghe, Van der Bracht, \& Van de Putte, 2016, p. 234). Within the social model it is the lived experience that is essential to further understanding and research of the barriers to independence and equality (Rosqvist, Chown, \& Stenning, 2020, p. 5).

The social model offers a 'simple, memorable and effective' idea (Shakespeare, 2006, p. 199). This simplicity makes it easy to explain and presents a 'clear agenda for social change' (Shakespeare, 2006, p. 199). However, as noted by Shakespeare (2006, p. 200), the model's simplicity is also its weakness. For example, a limitation of the social model is that it fails to identify impairment. Shakespeare pointed out that as early as 1992 Crow had argued that disabled people cannot simply pretend that their impairments are irrelevant (cited in Shakespeare, 2006, p. 200). For many disabled people their impairment is an important aspect of their lives and once the term 'disability' is located and understood as a form of 'oppressive social reactions' placed upon the impaired, 'there is no need to deny that impairment' or that 'in many situations both disability and impairment effects interact to place limits on activity' (Thomas, 2004, p. 29).

A second important limitation noted by Shakespeare (2006, p. 201) is the concept of a 'barrierfree Utopia'. Put simply, a world in which people with impairments are no longer disabled by barriers is hard to operationalise. For example, the sights and sounds of musical theatre will remain inaccessible for those lacking sight or hearing. Moreover, in some situations, different accommodations are incompatible with different impairments or indeed those with the same impairment may require different solutions (Shakespeare, 2006, p. 201). To highlight this, some individuals impaired by blindness may require Braille while others require large print or audio files (Shakespeare, 2006, p. 201). As such, in some situations, environmental change 
remains impossible, while in others, feasibility and resource constraints make other arrangements more practical (Shakespeare, 2006, p. 201).

Despite these limitations, services can and should be adapted wherever possible (Shakespeare, 2006, p. 202). The social model thus serves as a 'practical tool' rather than theory, idea or concept (Oliver, 2004, p. 30). From a management perspective, understanding barriers to social inclusion from the social model lens is important as it offers insight into the barriers faced by disabled people at both an organisational and societal level. Embedded in our argument is the premise that for managers to be effective agents for social inclusion they must understand disabled people beyond policy and the individual, by examining how people are disabled by societal factors. As such, this paper, drawing upon disabled stakeholders within the performing arts, offers a social inclusion framework to help further understand organisational and societal issues facing disabled people.

\section{Social inclusion}

Social inclusion ensures that everyone in society has opportunities, capabilities and resources to enable them to contribute to and share in the benefits of community or national development (Cultural Minister's Council, 2009). It has been argued that social inclusion can be achieved by taking actions to reach a moral imperative: leave no one behind and avoid the potential economic and social costs of exclusion (Report on the World Social Situation, 2016). Social inclusion is, therefore, seen as the process of providing opportunities to include people from all backgrounds, ensuring that they have the resources, opportunities and capabilities to work, learn, engage and have a voice (Australian Social Inclusion Board, 2012). Similarly, Barack (2010) sees social inclusion as provision of an equal opportunity platform for minority members to participate fully in all socio-economic activities.

\section{Social inclusion and its dimensions}

Social inclusion has no single definition, being interpreted in diverse ways. For this paper, we define social inclusion as a process with four interlocking dimensions in which everyone feels valued and has the opportunity to participate, for example, through performances, programmes or events, whether or not they have a disability. These four dimensions have been identified by scholars, but the four of them have not been discussed in a holistic manner, as far as the authors could determine. The next section provides a brief assessment of each dimension and its relationship to the arts. Although we analyse them separately, we recognise that there may be overlap in these dimensions.

\section{Access}

Access was first discussed in the UK during the 1970s and 1980s as part of the review of museum policy at the government level. The aim was to open cultural activity to a wider sector of people as audiences, according to Ames (1985), one of the earliest advocates.

In 1998, Sandell expanded this concept to the realm of social inclusion by suggesting that barriers to access of museums 'be removed by changing, for example, the ambience of the building, signage and the language used in displays' (Kawashima, 2006, p. 58). Access continued to be a concept mainly related to museums well into the 21st century. Kawashima (2006) discussed progress made over time with an economic focus, accounting for the decision to make museums and galleries free. Thus, financial barriers were eliminated, making museums open to all classes. Taylor and Bogdan (1989), early proponents of social inclusion for disabled people, said that access can be increased by interaction between those with and without disability. Their focus was the mentally challenged in the USA, while Kusayama was concerned about inclusion for the visually impaired in Japan. He found that accessible facilities for people with mobility difficulties are more advanced compared with those who have sensory difficulties (2005, p. 877). This 
paper is different in that it represents all disabilities, moves the location from museums to performing arts and deals with disabled people as audiences and performers.

\section{Participation}

Participation came a decade later, linking social justice to equitable participation in the arts (e.g., Putnam, 2000), often in museums (e.g., Sandell, 1998, 2003). It took until the early part of the 21 st century for the ways audiences participate in the arts to be examined. Scholars have investigated participation from various perspectives (e.g., Rentschler \& Hede, 2007; Sharma \& Varma, 2008; vom Lehn, 2010; Walmsley, 2016). Gidley, Hampson, and Wheeler (2010) consider participation to be the next step in social inclusion since it has a broader interpretation than access. They focused on the participation of Indigenous peoples and refugees (as well as disabled people) in sport, education and the arts, with social justice the ultimate aim. Lindelof (2015) was interested in not only why reaching broader audiences is important, but also how to find ways to reach them. However, the issue has rarely been examined from the perspective of disabled people themselves. Although a few studies on social inclusion of disabled people have been conducted in different countries with different research approaches (Fujimoto et al., 2014; Ruiz, Pajares, Utray, \& Moreno, 2011; vom Lehn, 2010), museums were generally the focus. One study on the participation of visually impaired visitors to museums (vom Lehn, 2010) concluded that interpretive resources such as labels, tangible objects and guides are insufficient to enable social inclusion in museums. Taken together, studies on participation suggest a need for a deeper examination of the methodological and theoretical foundations of social inclusion. This paper attempts to broaden the understanding of the issue by looking at it from the perspective of the very people who may feel excluded.

\section{Representation}

Representation has been a more recent development that links scholarly research in human dignity, potential and complexity to being recognised and included in society. Representation is defined as who does the speaking and how people are spoken of (Bacchi, 2009). Accordingly, representation is defined in two ways as: (i) the voice in discussion and decision-making, whether that's as an employee working in the arts or as a consumer of the arts (e.g., artists, managers and board director); and (ii) how disabled people are spoken about by others (Rentschler, Lee, Yoon, \& Collins, in press).

Regarding the former, including the voice of disabled people provides richness and depth to human capabilities and social contribution (Kuppers, 2005; Lindelof, 2015). Despite the need for representation for social inclusion, the voice of disabled people is absent from education, employment, community, arts and cultural accounts, including reflections on human rights for disabled people and representation of human dignity (Allan, 2005).

Regarding how people are spoken of, categories of knowledge, of which people are particularly important, often form the 'truth' of a subject and affect the way people think of themselves and others (Bacchi, 2009). Historically, representation of disability has been that of disposal or ridicule. Disabled people have long been used for entertainment purposes and dramatisation of what it means to be disabled (Bailey, 2011; Richardson, 2016). According to an article published by the Anti-Defamation League in 2005, disabled children were thrown under horses' hooves at the Coliseum, the 'ship of fools' which after sailing from port-to-port for public ridicule would abandon disabled people at the end of the tour and use disabled people in circuses and exhibitions for public humiliation. The infamous Bedlam mental asylum was one of 'London's favourite tourist spots, people entered the "Penny gates", roamed the yards and were "entertained or shocked according to their personal taste" (Scheerenberger, 1983, p. 44). Although such practices are no longer socially acceptable, forms of entertainment such as cinema, offered a 'safe, politically correct and ethically permissible forum for our curiosity' (Conn \& Bhugra, 2012, p. 55). As such, the inclusion of disabled people as both artists and audiences goes beyond mere access and 
participation. For example, supporting disabled artists not only improves the welfare of a minority group', 'it also allows disabled people as a whole to form a positive identity, not a tragic one, and helps re-conceptualise disability' (Bang \& Kim, 2015, p. 552) through representation.

\section{Empowerment}

This is also a more recent notion. Empowerment has been examined conceptually, calling for more research in this dimension (Themudo, 2009). More recently, empowerment has been examined in terms of museums (Malt, 2005) and in the non-profit context (Themudo, 2009), and at the individual, organisational and community levels (Zimmerman, 2000). At the individual level, the focus of our study, empowerment can assist in developing skills that enhance independence (Zimmerman, 2000). Empowerment can also be related to the social model of disability. Although disability is often viewed as a medical or individual problem (that which pathologises the individual as disabled and in need of medical intervention, treatment and, possibly, cure) (Clarke \& Van Amerom, 2008), the social model of disability is seen to provide individuals with the agency to overcome barriers to access, participation and representation. Empowerment enables people, especially those with disability, to move beyond seeing their engagement as therapy to a higher level where they negotiate a dignified, equitable and independent life. Hence, people can contribute to life in a positive manner through activities, including the arts (Evans, Bellon, \& Matthews, 2017). Yet, despite empowerment, segregation exists, which can be disempowering, creating barriers to inclusion. Hence, there is a need to review how the lives of disabled people are positioned vis-a-vis others in society, Table 1 summarises these four dimensions of social inclusion as identified in the literature: access, participation, representation and empowerment.

\section{Social inclusion of disabled people in the arts}

The arts are generally seen as a tool to engage people emotionally, bridging barriers and providing social experiences that have spill over effects at the individual, group, organisational and community levels, thus facilitating social inclusion (Azmat, Fujimoto, \& Rentschler, 2015; Chew, 2009). Recently, the universal relevance of disability presaged a new agenda in arts and cultural education (Bolt \& Penketh, 2016). They quoted Mitchell and Snyder as saying the 'disabled body' emerged as a 'potent symbolic site of literacy investment' (2016, p. 1).

Despite the potential of the arts to include people from all backgrounds, those benefiting from the arts still tend to be predominantly white, middle-class and privileged as has been mentioned by numerous scholars (e.g., Create London., 2018; Rankin, 2018). Authors (Azmat, Fujimoto, \& Rentschler, 2015; Gidley, Hampson, \& Wheeler, 2010; Kawashima, 2006; Kusayama, 2005; Lindelof, 2015) argue that diversity is under-represented in the arts, pointing out that those on the board, executives, staff and volunteers, and even those in the audience are mainly from the same narrow socio-economic group. This tends to reinforce social inequality, making it hard for 'the other' to gain entry to the arts industry, due to its gatekeepers, thus providing management with additional challenges for implementing inclusion. Although there is some focus in voluntary, non-profit institutions on the delivery of services for disabled people, there has been less interest in understanding the role of arts and disability. Furthermore, although national arts agencies and departments (Cultural Minister's Council, 2009; Hutchinson, 2005) have produced policies and strategies for disabled people, research on arts and disability remains sparse. In addition, from a total budget of over $\$ 200 \mathrm{~m}$, the Australia Council allocated only $\$ 1.3 \mathrm{~m}$ to arts and disability in 2018 (Rankin, 2018). To put this in perspective and illustrate the low priority given to it, while $20 \%$ of Australians live with a disability, only $2.3 \%$ of the Australia Council's budget is allocated to this sector. Despite the acknowledgement that the benefits of participating in arts extend beyond aesthetic norms, limited effort has been made to allow disabled people to interact 
Table 1. Four dimensions of social inclusion

\begin{tabular}{|c|c|c|c|}
\hline Access & Participation & Representation & Empowerment \\
\hline $\begin{array}{l}\text { Providing activities more } \\
\text { widely } \\
\text { Removing physical } \\
\text { barriers in buildings } \\
\text { and displays } \\
\text { Removing financial } \\
\text { barriers }\end{array}$ & $\begin{array}{l}\text { Audience } \\
\text { participation } \\
\text { Audience } \\
\text { development } \\
\text { Interpretive } \\
\text { resources }\end{array}$ & $\begin{array}{l}\text { Having voice } \\
\text { Being heard } \\
\text { How others speak } \\
\text { about disabled people } \\
\text { Being used as } \\
\text { entertainment }\end{array}$ & $\begin{array}{l}\text { Developing skills } \\
\text { Enhancing } \\
\text { independence } \\
\text { Giving individuals } \\
\text { agency to overcome } \\
\text { barriers } \\
\text { Positive contribution } \\
\text { through activities }\end{array}$ \\
\hline
\end{tabular}

with others and develop relationships where their disability is not seen as exceptional, which helps them feel included (Chew, 2009; Wiesel \& Bigby, 2016).

Disabled people in the arts are becoming more vocal about social inclusion, demanding it or being prepared to protest at exclusion, within the framework of Australian social policy. The National Disability Insurance Scheme (NDIS) was introduced in 2013 as a federal government policy reform, and as a means of empowering disabled people by providing them with certainty of support (Addis, Michaux, \& McCutchan, 2018). It oversees social inclusion for individuals but also more generally established a network of supports for disabled people (Bonyhady, 2014; Ryan \& Collins, 2008). At the same time, institutional reforms were undertaken which increased the size and importance of the voluntary sector for service delivery. Many of the arts organisations, where these changes took place, fall into the category of voluntary, independent, non-profit or government organisations. Such changes were accompanied by growing public awareness for and support of social inclusion for disabled people a shift in the role that arts organisations and their management play in communities regarding access, participation, representation and empowerment (Cultural Minister's Council, 2009; Gooding, Anderson, \& McVilly, 2017).

\section{Method}

We undertook a qualitative study to explore social inclusion of disabled people in performing arts through personal testimonies. The voices of disabled people are foregrounded, along with other stakeholders (Allan, 2005). The relevance of employing qualitative enquiry while studying social phenomena has been emphasised by several authors (Bogdan \& Biklen, 1992; Naraine \& Lindsay, 2011) to capture richer participant experiences and gain understanding of their unique personal and social experiences in an area that is largely unexplored (Glesne \& Peshkin, 1992; Stake, 1995). Similarly, our study aimed to gather information regarding the personal experiences of people with and without disability in order to foreground their views.

\section{Data collection}

Our study included 34 semi-structured interviews with participants: (i) disabled audiences $(n=$ $14)$; (ii) carers $(n=4)$; (iii) disabled performers $(n=4)$ and (iv) stakeholders such as staff, fundraiser/developer, managers, artistic manager, former and current board directors with and without disability involved in performing arts organisations $(n=12)$. Table 2 shows the data sources, their insights in the study and some demographic characteristics such as gender and types of disability (as being mobility, hearing impairment, visual impairment and multiple impairments) for the participants. Our stakeholder interviewees were drawn from arts organisations on a publicly available list on the website of Arts Access Australia, identifying arts organisations which engage with disabled people. We obtained approval from four arts organisations to interview their staff, performers with disability and board members. Interviewees were purposively selected from amongst 
Table 2. Data sources and participants

\begin{tabular}{|c|c|c|c|}
\hline $\begin{array}{l}\text { Process } \\
\text { (semi-structured } \\
\text { interviews) }\end{array}$ & Participants & $\begin{array}{c}N=34 \text { ( } 1 \text { individual } \\
\text { was both an } \\
\text { organisational } \\
\text { stakeholder and a } \\
\text { performer) }\end{array}$ & Profile \\
\hline $\begin{array}{l}\text { Organisational } \\
\text { stakeholders }\end{array}$ & $\begin{array}{l}\text { These participants have } \\
\text { expertise in performing } \\
\text { arts in theatre, dance as } \\
\text { artistic administrators, } \\
\text { managers and } \\
\text { policy-makers, working in } \\
\text { different organisations }\end{array}$ & $N=12$ & $\begin{array}{l}6 \text { females } \\
6 \text { males } \\
\text { Impairment: } \\
\text { Mobile: } 1 \text { female }\end{array}$ \\
\hline $\begin{array}{l}\text { Disabled audience } \\
\text { members }\end{array}$ & $\begin{array}{l}\text { These participants attended } \\
\text { performances for arts } \\
\text { events }\end{array}$ & $N=14$ & $\begin{array}{l}8 \text { females } \\
6 \text { males } \\
\text { Impairment: } \\
\text { Mobility: } 4 \text { females, } 1 \text { male } \\
\text { Visual: } 1 \text { female, } 2 \text { males } \\
\text { Hearing: } 3 \text { females } \\
\text { Multiple: } 1 \text { female }\end{array}$ \\
\hline Carers & $\begin{array}{l}\text { These participants attended } \\
\text { arts performances with } \\
\text { disabled audiences and } \\
\text { had insights related to } \\
\text { barriers for disabled } \\
\text { audiences }\end{array}$ & $N=4$ & 4 females \\
\hline $\begin{array}{l}\text { Disabled } \\
\text { performers }\end{array}$ & $\begin{array}{l}\text { These participants performed } \\
\text { at arts events }\end{array}$ & $N=5$ & $\begin{array}{l}4 \text { females } \\
1 \text { male } \\
\text { Impairment: } \\
\text { Mobile: } 4 \text { females } \\
\text { Multiple: } 1 \text { male }\end{array}$ \\
\hline
\end{tabular}

those who engaged with disabled people across different roles, and were sourced, using the snowball sampling technique. For example, we asked friends and colleagues for recommendations for participants with disabilities (Merriam, 1990) thus starting with individuals who had the desired characteristics and used their connections to recruit other participants with shared characteristics for our study (Sadler, Lee, Lim, \& Fullerton, 2010). Participants in the study were asked to share research information with other participants they knew who might be eligible for the study. Participation in the study was voluntary and each participant's disability was taken into consideration when conducting the interviews so as to ensure a safe environment.

For each of the four participant groups, a semi-structured interview guide was prepared in order to explore and compare their experiences regarding social inclusion. However, the primary objective was to encourage participants to lead the conversation in a way that was important to them when recounting their inclusion experiences (McGrath, Palmgren, \& Liljedahl, 2019). A semi-structured interview guide started with brief demographic background information relevant to the study (e.g., career history; education; ability or disability; gender and age) and followed by warm-up questions to build rapport (Bell, 2014; Schoultz, Säljö, \& Wyndhamn, 2001) such as: 'How often do you go to programs offered by performing arts organizations?', 'How do you obtain needed information?', 'Do you go to events by yourself or with a carer?' If they answered 'with a carer', an additional interview was conducted with the carer, with their consent. The main interview questions regarding social inclusion of disabled people emerged from related literature, including Bang and Kim (2015); Bolt and Penketh (2016); Naraine and Lindsay (2011); Lindelof (2015) and Woods (2017). Some of the questions asked were: 'Was it easy for you to be an audience member at performing arts programs? Why/why not? Please give examples'. 'Did you feel 
included? If not, why not? Please give examples'. 'What were some of the challenges experienced from being a disabled audience member at those programs? Please give examples'. Most questions were followed-up to elicit details about their experiences.

As for stakeholders, questions such as 'What are the barriers/issues from your organisation's perspective with regard to social inclusion for disabled people?' and 'What do you think are the ongoing challenges for social inclusion for the future of your organization?' Finally, for disabled performers, questions such as: 'What recommendations can you provide to arts program stakeholders as an active performer with physical disability (e.g., mobile disability, visually impaired, hearing impaired)? Please give examples'. Thus, the aim was to obtain their views regarding the scenario and elicit suggestions for improvement.

The interviews lasted around 40-50 min, were digitally recorded and transcribed. We interviewed until data saturation was achieved. Data saturation was reached with 10 respondents in each group with the exception of carers and disabled performers.

This study was undertaken in line with university research ethics committee requirements. We recognise the limitations of the methodology by using an interpretive approach which generalises to theory rather than to a population or sample. We recognise the limitations of using an interpretive approach.

\section{Data analysis}

Interviews were transcribed and were first read in full and coded manually into themes. We took a holistic approach to concept development, devising first-order and second-order analysis by coding themes, following a two-stage approach in analysing data (Williams \& Murray, 2015). First-level coding followed a thematic approach. Second-order coding took themes from the first-order coding, using the four dimensions of social inclusion as a framework for analysis (Braun \& Clarke, 2006). The use of researcher and researched voices enabled links between data and induction of new concepts, confirming the rigour of concept development and theory building (Williams \& Murray, 2015). Having multiple authors enabled the data analysis stage to be thorough and trustworthy by clarifying points such as the meaning of quotes, by building on identified themes.

\section{Findings}

This section discusses themes arising from interviews with representative quotes from the respondents (using pseudonyms) as evidence.

\section{Barriers to social inclusion}

Evidence collected from the interviews identified numerous barriers to inclusion. The issues identified fit within the four tenets of social inclusion - access, participation, representation and empowerment. This section identifies those barriers and extends them via evaluation of other barriers to inclusion.

\section{Barriers to access}

Barriers to access included elements such as physical barriers, uncertainty, lack of awareness and reference group attitudes. Although physical needs of disability, in comparison with cognitive, are more recognised, understood and addressed, physical barriers remained a central reason disabled people were unable to access a performance/event. Physical barriers were encountered before arriving at the event. For example, car parking was an issue regarding the number of suitable car parks, size of allocated parks and their location. Once at the event, further physical barriers were encountered: Matt, an audience member with a mobility disability shared his insights about seating: 
It is difficult because the seats are narrow. You don't have much legroom [There is] no back support [for] the seats. It is an old theatre [with] stairs.... [It] was designed in an age where disabled people were not out and about (Matt).

As evident in Matt's example, recognition that physical barriers exist is attributed to previously held views of disability. Although it should be acknowledged that some buildings are limited by issues such as heritage listing, and or space, awareness of barriers such as those highlighted by Matt need to considered. If the barrier cannot be eliminated, an alternative can be implemented. This is an issue we explore further when discussing participation.

There were also institutional barriers, such as steps into venues. For example, Bertie, a blind audience member said: 'steps are everywhere. Poles are always my greatest fear'. Furthermore, a female audience member with a physical disability supported this view, stating that steps caused her 'to make phone calls and enquiries to make sure you can get to your seat' (Ellen). In other words, findings suggest insufficient thought has been given to building design or interior design for all people, creating barriers to inclusion, which aligns with the tenets of social model of disability.

Findings further suggest that physical barriers also create issues during the performance. For example, the physical challenges associated with intermission combined with theatre policy mean that some disabled audience members go without basic needs, such as water:

it takes me so much longer to get down the stairs to go to the bathroom or to grab a drink in intermission ... [So] I go without (Matt).

In addition to not being able to satisfy basic needs such as access to water, the inability to participate in intermission limits potential social interaction with other audience members. As such, barriers that limit access also limit the ability of disabled attendees to extend their social networks, be seen by others as participating members, decode interpretations of art through interpersonal interactions and expose non-disabled counterparts to their views of the event.

Barriers to inclusion also included reference group attitudes. Reference group attitudes influence the availability and opportunity to access activities and can include attitudes regarding the appropriateness of the activity (Crawford \& Godbey, 1987). A common reference group attitude was found to be age (i.e., age restrictions). Although some programmes had positive impacts, age restrictions often meant that once disabled people reached a certain age, they were no longer eligible to be part of the programme. For example, Raylene shared her view of the limitations of participation in disability theatre, 'the bit that's sad about it .... is that it [participation in disability theatre] stops at 27 . It's a great drawback'.

Others with invisible disabilities (or their carers) considered access needs were not properly understood, feeling more like 'box ticking' than inclusion. For example, one carer, Heide, told us that her son 'could not see' as he was 'way up the back' in the theatre. As she advised, there was no awareness of how to accommodate him, going so far as to say that the toilets were also not accessible' or 'not unisex' thus preventing carers from the opposite sex providing needed assistance. Simple solutions can include signage in 'braille' or a 'tactile map' or 'audio descriptions' of where toilets or amenities are located, as one blind audience member, Kerry, advised. Along this line, disabled performers discussed how transparency in the sector would allow them to communicate their access needs:

I'd like to see the sector change so that there's better access: those who identify as disabled artists (should) be able to book without being penalized (Amy). 
Access was not only an issue for artists with disability. Customers were also entitled to it. Although safety is an essential customer right, disabled audience members spoke of concerns regarding their physical safety:

I would be concerned if there were an emergency because I would not have somebody to assist me. ... I never go by myself because of access (Matt).

In other words, human safety is a concern as well as convenience and comfort. Therefore, arts venues require special signposting for the benefit of disabled people or designated helpers to aid disabled people in the case of an emergency. Moreover, extra effort should be made to ensure that disabled people are aware that these measures are in place so that they feel more comfortable about attending performances at the venues.

In sum, barriers to access entailed structural barriers (e.g., parking, seating and signage), which can be explained by the social model in that they are produced and designed by society with little awareness of the needs of disabled people. Although the barriers identified were numerous, it should be noted that this is a limitation of the social model - not all disabled people will face the same barriers - so at times solutions for one may be incompatible with another. Although this limitation can sometimes provide complex or insurmountable challenges, it should not result in a dismissive approach nor prevent management (or other stakeholders) from eliminating, attempting to reduce or mitigating access barriers.

\section{Barriers to participation}

As with access, barriers to participation emerged as a theme for all stakeholders. What was evident within themes relating to participation was just how distinct (and important) a category was when compared to access. For example, representation, exposure and understanding of disability impacted how disabled people who had access could participate in artistic performances. Although participation was not denied, even accommodated, the way in which it was done was often viewed by the provider as a nuisance.

Although access was sometimes available, participation was dependent on the assistance of staff and/or a 'carer'. When assistance was needed to negotiate barriers in-place, disabled audience members were often made to feel as though their presence was a burden. For example, as stated by Holly, an audience member with a physical disability: 'The person who had to open a special door behaved like it was a hassle'. Such attitudes limit the inclusion of disabled people and reflect the values of neoliberalism and capitalism - a society that values independence and achievement (Oliver, 1990). These dimensions are seen to empower individuals but ignore complex social relations and structures within a society dominated by able-bodied mindsets and assumptions. Thus, approaches to independence are problematic, and gaining acceptance (or understanding) is difficult in a climate where 'stigma may be exacerbated by heightened public stinginess toward those deemed unproductive or burdensome' (Blum, 2007, p. 203).

Extending feelings of being a 'hassle', an important issue concerning the participation of disabled audience members was their treatment as second-class citizens. The following quote from Louise, an audience member with a physical disability explains that lack of respect can be a barrier as disabled people are ignored, being treated as if they were invisible:

[There can be] a lack of respect because you have a disability. People have patterns of thinking. For example, I go to a ticket counter and ask a question. If someone is there with me, the person behind the counter won't answer directly to me ... There is a need for awareness and training for staff.

Although an indirect barrier to inclusion, the passive avoidance of speaking directly to a disabled attendee highlights a prominent issue regarding the participation of disabled audience members. 
A more active form of avoidance created a barrier due to misunderstandings, identified by Bertie who stated:

People who work on the door always think I'm drunk, because I'm not looking at them directly or I'm struggling to find my way up the steps ... it happens a lot.

Such misguided perceptions of barriers to participation were troubling, indeed upsetting for the disabled people we interviewed, limiting their experience at the arts event.

The continuing stereotypical images of disabled people and dominant culture of those without disabilities contribute to misunderstanding and fear of disabled people as well as the underlying notion that disabled people are considered second-class citizens. This can be summed up in the comment: 'the more difficult one, of course, is getting past people's prejudices and fears'. Extending this view, one disabled person explained: 'people should be more aware that there are disabled people out there and that... it's more than disabilities you can see, it is also disabilities you can't see' (Matt). In other words, barriers are not only overt and visible, but also covert and invisible, highlighting the complexity in removing them, as they entail not only physical things but also attitudes that people hold.

Participation was also inhibited by normative expectations of time and work. As argued by Sen (1985), inclusion is often dependent on an individual's ability to function in a manner deemed valuable to the economy. For disabled artists in our study, it was often not that they couldn't do the task, it was when and how the task was expected to be performed that inhibited them:

If you can't start at 9 o'clock in the morning you are penalized (Moses).

Furthermore, for disabled artists, the ability to access opportunities was often circular. For example, the ability to be included was dependent upon their ability to fund their art; but their ability to fund their art was dependent upon being able to participate within a normative structure.

Access to work and other opportunities was dependent on the ability to meet normative standards which pertain to 'restriction of access to opportunities and limitations of capabilities required to capitalize on the[m]' (Hayes, Gray, \& Edwards, 2008, p. 9).

For example,

... you end up not taking opportunities because you have to financially back yourself. Take Melbourne. I booked eight nights' accommodation for two shows ... An able-bodied person would be there for two days ... You can't do your festival circuit like everyone else, you don't make money like everyone else (Amy).

In sum, barriers to participation entailed attitudinal barriers that include: ignorance, prejudice and simple lack of knowledge about what to do to create a more inclusive environment for disabled people. This indicates that much remains to be done to enable more disabled people to participate in art activities. Even more so than numbers, it is the quality of participation that needs to be addressed in the effort to improve the health and well-being of disabled people.

\section{Barriers to representation}

Representation of categories such as disability have real effects on society (Bacchi, 2009). Cultural attitudes towards disability are part of a disabling environment that imposes social barriers beyond any individual impairment (Barnes \& Sheldon, 2010; Oliver, 1990). In addition to cultural attitudes, the absence of voice was also a barrier to inclusion. Recognising this, we now highlight key inclusion barriers associated with representation. 
Both disabled audience members and performers discussed a lack of awareness amongst staff about the different types of disability and capabilities and the way to handle them which impacted their representation:

So many people don't feel capable of saying that in an able-bodied community because then you're the difficult one ... You're the princess (Amy).

The lack of voice, or feelings about how their voice would be interpreted imposed both intrapersonal and interpersonal barriers upon disabled stakeholders. In short, disabled people, as in this quote, expressed the view that they are often viewed as inadequate or a burden on society. This is reflective of assumptions embedded within a neoliberal culture and a further example of tension, or conflict, that arises when structure is ignored (or assumed) and individual responsibility paramount. Disabled people may not 'obey' the inherent social norms of society and their impairment is often viewed with pity and/or disgust (Park et al., 2003). A desire to change such perceptions was evident from a disabled artistic director:

Living with an impairment is not a tragedy, it's not something to feel sorry for, we don't want pity, rather envisage performers as professional dancers (Mary).

The point about the importance of the artist being more important than the disability was made repeatedly by performers, arts managers and artistic directors. There is a growing view by disabled people in the arts that they are capable, strong, professional and pursuing a career, rather than undertaking therapy, as was once the dominant view (Solvang, 2018). Nonetheless, despite the potential for arts programmes to benefit disabled people and instigate social change in the wider community, arts programmes for disabled people are still not 'taken seriously in terms of their artistic outputs and merits' (Darcy, Maxwell, Grabowski, \& Onyx, 2019, p. 1). Attitudes to work by disabled artists were evident in our interviews with performing artists, particularly when they did not want to be known as disabled artists. For example, in an interview with Moses, the issue of the seriousness of his work as an artist was important:

... often people won't take work that's coming from a disabled artist as seriously as work that's coming from an able-bodied artist. I let things stand on their merits ... I was a nondisabled artist for a long time before I became disabled.

In other words, the complexity of artistry for disabled people is exemplified in this quote. Feelings about barriers to disabled people participating in the performing arts were not limited to the individuals themselves. For example, in our interview with Amy, a disabled artist, spoke of how ableist structures influence the experiences of disabled people at elite cultural events such as awards nights:

An incident happened where the actress winning the award was called to collect it. Then they realized, oh, she can't get up on stage. She had to come onto the stage from backstage. She didn't have the grand entrance like everyone else. She was an outcast. They should've thought about that. They knew she was up for an award. She's clearly disabled. She had a good chance of winning. The argument was that the people that built the theatre wouldn't have thought about that (Amy).

The needs of disabled people and their voices were overlooked in event planning. Consequently, past mistakes are repeated and used as an excuse for present shortcomings. In sum, barriers to representation entailed how disabled people are spoken about and thought of (e.g., negative notions, ideas and concepts), which tends to reinforce the social model produced by the enabled 
majority. Second, representation is not just how disabled people are spoken of, but who does the speaking. In order to expand representation of disabled people it is imperative that the mindset and outlook of society, in general, be changed regarding awareness of the difficulties faced by disabled people. This can, in part, be achieved by increasing the voice of disabled people and their representation amongst key decision-makers. The findings suggest there is still a long way to go to ensure that representation creates inclusion for all.

\section{Barriers to empowerment}

As discussed earlier, the four tenets of social inclusion are intertwined. For example, barriers to access created barriers to empowerment. As identified by participants such as Muge, a staff member in the disability sector, the performing arts bring with them the ability to foster independence through methods such as increasing physical capabilities, education and training. Although the focus of art and disability has been to position the practice of art as one of therapy and/or leisure (Bullock, Mahon, \& Killingsworth, 2010; Solvang, 2018), limiting art to its therapeutic value, restricts what the practice can offer. As stated by Brian who is the disabled manager of an advocacy organisation for arts and disability:

Disability arts has come from a place of therapy where the modus operandi is to 'keep them busy; give them something to do.' I don't want to disparage that there's therapeutic value. But it's more than that: how can we create an environment that supports disabled artists to flourish and grow?

All stakeholder groups talked about awareness-building of staff to enable them to adapt to disabled people, as a means of over-coming barriers, thus empowering them. For example, 'there should be respect and inclusion in greeting and placement of people in advance' (Louise). Such views were not limited to introductions but also considered important in building the whole arts experience. A blind audience member said:

In training, it is not just what can happen in the physical environment but getting people to think about their attitudes and understand that disabled people have a lot to offer as audiences (Bertie).

In short, this quote and the one by Brian, demonstrate that their art, rather than their disability, is an intrinsic aspect of their identity, developed through performance. Further evidence for the importance of empowering the voice of disabled people was that disabled people often found it difficult to voice their own needs:

It's difficult to voice my access needs. That's something I have to work on. But there are barriers. That's why artists who identify as disabled stick together (Amy).

Our findings suggest that disabled people are a market segment that is overlooked or ignored. The need for awareness, respect and change in attitudes in overcoming barriers for disabled people is reinforced by a disabled performer, Eve, stating that 'people with disabilities need not be feared. They have the capability to bring funds to your organization if only you will ask them and provide them the means to attend your programs'. This is a powerful statement which reinforces the importance of removing barriers to empowerment, so that disabled people can contribute to arts organisations more fully.

In our findings, barriers to empowerment entailed how disabled people are given agency for their actions (e.g., development, training, paid work and even recognition). Disabled people want to have the same rights and opportunities as their able counterparts. When considering disabled artists, while it should be acknowledged that for some disabled people their impairment is part of 
their identity, a limitation of the social model, for the artists in our study, they want to be recognised as artists (who just happen to have an impairment), not as disabled artists. Identity for disabled people, and how it links to barriers such as empowerment and representation is a complex matter that needs further research.

\section{Bringing together the findings}

In response to our research question - what are the barriers to social inclusion for disabled people in the performing arts - our findings have led to the development of an empirical framework. We call it the APER (Access-Participation-Empowerment-Representation) framework (Figure 1) for management of key barriers to social inclusion. As can be seen by the examples provided in Figure 1, barriers related to each aspect of social inclusion were viewed through the social model of disability: societal barriers that require change.

We found that the barriers for social inclusion within the arts occur across the four dimensions - access, participation, representation and empowerment - which are interdependent and intertwined. For example, barriers to access, such as not being able to access certain events or areas, impact participation. Barriers to participation, such as normative expectations, restrict how and when artists with a disability can showcase their work, thus impacting how they are represented. Moreover, in addition to access impacting participation and participation impacting representation, we argue that the model works both ways. For example, the representation of disabled people in the arts impacts participation - such as how cultural attitudes influence interpersonal experiences (e.g., not being spoken to directly).

We placed empowerment at the end of the framework as empowerment 'seeks to maximise the potential of each human being' (Gidley, Hampson, \& Wheeler, 2010, p. 4). As with the other dimensions, we argue that while access, participation and representation influence empowerment, the reverse can also be true. By removing the earlier barriers, a person's pathway is enhanced. When a person's pathway is enhanced their motivation to pursue their goals increases (Egan, Butcher, \& Ralph, 2008, p. 35). If more disabled people are empowered to engage in the performing arts (whether as staff, performers or audience members) it increases their representation and a form of representation is self-generated.

\section{Discussion}

Despite the emerging focus on including disabled people as is evidenced in the NDIS and other policies, the potential for the arts to include disabled people through the removal of barriers remains somewhat underexplored. Within this context, this study examined the barriers to social inclusion for disabled people in the arts drawing on the responses of multiple stakeholders including disabled people as audiences and performers through the lens of the social model of disability. The strengths of this paper lie in the fact that it includes views of disabled people who are most affected by the barriers, thus shedding light on the efficacy of policies and processes that currently are in place and the barriers faced. Our paper shifts the focus away from museums to performing arts for the social inclusion of disabled people.

Although empowerment is the end goal, each dimension is important. For example, despite barriers regarding access being the most easily recognised and addressed, access barriers remain. Some access barriers can be alleviated through greater funding (Rankin, 2018); however, a shift in attitude is required to make distribution of funding more equitable. Although access occurred in some situations, access alone did not result in social inclusion.

Moreover, we found that barriers to participation put limits on the positive impacts of access, such as a sense of belonging, human dignity and potential future involvement of disabled people. Attitudes towards and understanding of disability were evident concerning participation. The circular nature of participation was prescriptive and descriptive of understandings of disability. By 
this we mean that how disabled people were invited to participate reflected understandings of disability and prescribed how they were perceived (and treated). The prescriptive and descriptive findings of participation highlight connections between each of the barriers to inclusion.

Barriers associated with representation were linked to dominant discourses in the arts and its associations with therapy. Although not ignoring the arts' therapeutic potential, it limits the potential social inclusion in the arts can offer management in organisations, as our findings indicate. Moreover, if representation of disabled people within the arts is limited to the restoration of disabled people with the aim of creating a person who participates within a normative structure, or something that must be accommodated in order to be politically correct, it restricts how disabled people are perceived and perceive themselves. Each barrier to inclusion (access, participation and representation) impacted empowerment. Lack of voice and desire to limit interactions to those who were members of the disabled community were examples of this. Negative attitudes as well as the lack of respect faced by disabled people emerged in disabled people, audience and performer accounts. Such a finding stresses the need for management change that other organisations can take up, to ensure full inclusion of disabled people. Future research needs to address ways to overcome barriers that relate to the four-dimensional approach to social inclusion identified in this paper (Kawashima, 2006; Lindelof, 2015; Themudo, 2009).

Although bringing together our findings led to the development of the barriers to inclusion framework, we recognise the limitations of our study. First, we understand a qualitative study cannot be generalised. However, we have generalised to theory, making advances in understanding disability and society in the arts ecology. A second limitation is the study breadth, which included a number of different types of stakeholders (and thus potentially also its limitations). As noted by Camarero, Garrido, and Hernández (2020), the missions of arts organisations are socially focused, with objectives that are both social and economic. As a result, their stakeholder lists are long and complex. Therefore, additional research could be undertaken to develop the framework further, through studies that consider stakeholders separately: in particular, disabled audience members and/or consumers, disabled artists and performers, as well as the awareness, understanding and attitudes of managers regarding the inclusion of disabled people.

Finally, it should be recognised that the model being embedded within the social model is itself a limitation, in particular, the idea of a 'barrier-free Utopia' (Shakespeare, 2006, p. 201). Although not all barriers to inclusion can be removed and limitations such as differing and sometimes incompatible accommodations still remain, the framework presented offers clear and segmented starting points regarding managerial change, or, as identified below, a tool that can be used to achieve wider organisational goals.

\section{Implications for management}

As all the barriers that emerged in our findings relate to the social model of disability, implications for management are profound, necessitating change in policy and praxis. The implications for management entail undertaking an integrated approach to include disabled people focusing on multiple levels as opposed to a fragmented single level focus (Syed \& Kramar, 2009). At the micro-level managers need to engage disabled people in the development and updating of policies and procedures and listen to their voices to not only include them in workforce, but also to facilitate their access, participation, representation and empowerment in workplaces. Including disabled people in the management of art ventures would ensure their participation in decision-making and also empower them, which is central to the social model. Although these policies, processes and procedures are not new for management, enacting them does seem to be new and they are much needed in relation to disabled people.

At the meso-organisational level, managers could focus on raising staff awareness of the needs of disabled people, training and development of staff in understanding disabled people and making necessary changes to remove the barriers. As shown in Figure 1, these matters create an 
inclusive workplace. Finally, at the macro-level, there is also scope for managers to influence and work with government and other policy-makers on the inclusion of disabled people. Such an integrated approach has implications for managers to understand them beyond policy and the individual, by examining how people are disabled by societal factors through focus on meso and macro levels.

Furthermore, different types of barriers, and how they are interrelated may assist management in achieving wider organisational, and or societal, goals, for example, the UN Sustainable Development Goals (SDGs). As argued by Dalton (2020), the complexity of the SDGs may impede small to medium enterprises from engaging with this framework. Simpler tools, such as the barriers to inclusion framework presented in this paper, may assist management with areas they need to address. An example is Dalton (2020) and her examination of Sydney Theatre Company. Although the UN SDG 8.5 articulates that:

By 2030, achieve full and productive employment and decent work for all women and men, including for young people and persons with disabilities, and equal pay for work of equal value

as Dalton (2020) finds, current meso-organisational measures may not capture information around disabled people. Accordingly, in the sector, there may be a disconnect between macroorganisational policy, and despite the best organisational intentions, the micro-level outcomes and opportunities for disabled people at the meso-organisational level.

Finally, at the macro-level there is also scope for managers to influence and work with government and other policy makers on the inclusion of disabled people. Such an integrated approach has implications for managers to understand disability beyond policy and the individual, by examining how people are disabled by societal factors through their focus on meso and macro levels.

\section{Conclusion}

This paper provides support for the notion that disabled people in the performing arts face a range of barriers to their inclusion, establishing a framework that suggests barriers fit into one of the four overarching types: access, participation, representation and empowerment (APRE). Although there have been previous studies investigating social inclusion generally, as well as in the arts sector specifically, to the authors' knowledge this is the first attempt at positioning the barriers into an overarching explanatory typological frame. More notably, the APRE framework may have potential as a starting point to contribute to further refinement and consideration of the social model of disability. For example, Shakespeare (2006) critiques the social model in relation to its blunt nature, arguing that it lacks nuanced consideration and understanding of the complexity inherent in social inclusion. The APRE framework provides one of the first models that can add nuanced consideration in this space, addressing one weakness of the social model by suggesting an interactive typology of four distinct, but inter-related, barriers to inclusion.

As this is the first study of its type, the need for replication of the framework, both across sectors and within the arts sector, has been identified as a priority for further exploration and refinement.

In terms of practical implications, a key intervention for management to facilitate inclusion is by engendering hope (Gidley, Hampson, \& Wheeler, 2010), a prime action from the national disability policy, that, in relation to the APRE frame, can be facilitated by empowering individuals. Empowerment is likely to have a positive impact on motivating people to think about their pathway in life (Egan, Butcher, \& Ralph, 2008, p. 35). In conjunction with access, participation and representation, empowerment provides the final part of the jigsaw puzzle of creating an integrated approach. This framework (APRE) can demonstrate how social inclusion in the arts has 
developed from a simple economic argument to a more nuanced understanding of not only why social inclusion is important, but also the barriers to its attainment.

The arts can contribute to communication, acknowledging disabled people human dignity and the significance of their social contribution (Bolt \& Penketh, 2016). Our study, therefore, provides implications for organisations to become 'truly inclusive' (Kawashima, 2006; Ryan \& Collins, 2008), moving beyond social justice to maximising human potential. Thus, working to remove the barriers identified in our study will provide the first small steps to providing greater hope to a significant group of people in society.

We wish to signal the breadth of this study, which included a number of different types of stakeholders (and thus potentially also its limitations). As noted by Camarero, Garrido, and Hernández (2020), the mission of arts organisations is socially focused, with objectives that are both social and economic. As a result, their stakeholder lists are long and complex (Camarero, Garrido, \& Hernández (2020). Therefore, additional research could be undertaken to develop the framework, through studies that consider stakeholders separately: in particular, disabled audience members and/or consumers, disabled artists and performers, and, the awareness, understanding and attitudes of managers regarding the inclusion of disabled people.

Our framework helps to better understand and conceptualise inclusion issues facing disabled people. The key barriers identified in our study related to each of the four dimensions of social inclusion which can be explained by the social model of disability reinforcing that people are disabled by society, with barriers that range from physical to attitudinal. These findings have implications beyond social inclusion within the arts and demonstrate how the arts can empower disabled people and enable them to access, participate and represent themselves and have a voice if barriers are removed. As a final note, it is important to acknowledge that the barriers presented are not limited to disabled people and may indeed be applied to any individual or group facing barriers to inclusion. As such, considering this frame across a diverse range of individuals and contexts would be an important step to more fully understand barriers to inclusion in a more holistic way.

\section{References}

Addis, R., Michaux, F., \& McCutchan, S. (2018). Scaling impact: Blueprint for collective action to scale impact investment in and from Australia. Melbourne, Australia: Australian Advisory Board on Impact Investing, Impact Investing Australia.

Allan, J. (2005). Inclusion as an ethical project. In S. L. Tremain (Ed.), Foucault and the government of disability (pp. 281297). Ann Arbor: University of Michigan Press.

Ames, M. M. (1985). Deschooling the museum: A proposal to increase public access to museums and their resources. Museums International, 37(1), 25-31.

Anti-Defamation League. (2005). A brief history of the disability rights movement. Accessed July 5, 2017. https://www.adl. org/education/resources/backgrounders/disability-rights-movement.

Australian Social Inclusion Board. (2012). Social inclusion in Australia: How Australia is faring (2nd ed.). Canberra, ACT: Department of the Prime Minister and Cabinet, Commonwealth of Australia. doi: https://library.bsl.org.au/jspui/bitstream/1/3170/1/Social\%20inclusion\%20in\%20Australia\%20how\%20Australia\%20is\%20faring2012.pdf.

Azmat, F., Fujimoto, Y., \& Rentschler, R. (2015). Exploring cultural inclusion: Perspectives from a community arts organisation. Australian Journal of Management, 40(2), 375-396.

Bacchi, C. (2009). Analysing policy. Frenchs Forest, NSW: Pearson Education.

Bailey, M. (2011). 'The illest': Disability as metaphor in hip hop music. In C. M. Bell (Ed.), Blackness and disability: Critical examinations and cultural interventions (pp. 141-148). East Lansing: Michigan State University Press.

Bang, G. H., \& Kim, K. M. (2015). Korean disabled artists' experiences of creativity and the environmental barriers they face. Disability \& Society, 30(4), 543-555.

Barack, M. M. (2010). Managing diversity toward a global inclusive workplace. Thousand Oaks, CA: Sage.

Barnes, C., \& Sheldon, A. (2010). Disability, politics and poverty in a majority world context. Disability \& Society, 15(7), 771-782.

Barraket, J. (2005). Putting people in the picture: The role of the arts in social inclusion. Melbourne, Australia: University of Melbourne: Centre for Public Policy.

Bell, J. (2014). Doing your research project: A guide for first-time researchers. Berkshire: McGraw-Hill Education.

Blum, L. M. (2007). Mother-blame in the Prozac Nation raising kids with invisible disabilities. Gender \& Society, 21(2), $202-226$. 
Bogdan, R. C., \& Biklen, S. K. (1992). Qualitative research for education: An introduction to theory and methods. Boston: Allyn and Bacon.

Bolt, D., \& Penketh, C. (2016). Disability, avoidance and the academy: Challenging resistance. New York: Routledge.

Bonyhady, B. (2014). The national disability insurance scheme: A catalyst for large scale, affordable and accessible housing for people with disability. Housing, Disability and the NDIS Forum, 27 March 2014, Canberra.

Braun, V., \& Clarke, V. (2006). Using thematic analysis in psychology. Qualitative Research in Psychology, 3(2), 77-101. doi: $10.1191 / 1478088706 q p 0630 a$

Bullock, C. C., Mahon, M. J., \& Killingsworth, C. L. (2010). Introduction to recreation services for people with disabilities: A person-centered approach (3rd ed.). Champaign, IL: Sagamore Publishing.

Camarero, C., Garrido, M., \& Hernández, C. (2020). The mixed effects of organization's and manager's social capital: Evidence from the case of museums. Journal of Management \& Organization, 26(4), 601-624. doi: 10.1017/jmo.2017.77

Chapman, R. (2020). Neurodiversity, disability, wellbeing. In H. B. Rosqvist, N. Chown, \& A. Stenning (Eds.), Neurodiversity studies: A new critical paradigm (pp. 7-72). New York: Routledge.

Chew, R. (2009). Community-based arts organisation: A new center of gravity. Washington, DC: Americans for the Arts.

Clarke, J., \& Van Amerom, G. (2008). Asperger's syndrome: Differences between parents' understanding and those diagnosed. Social Work in Health Care, 46(3), 85-106.

Congreve, S., \& Burgess, J. (2017). Remote art centres and Indigenous development. Journal of Management \& Organization, 23(6), 803-820. doi: 10.1017/jmo.2017.66

Conn, R., \& Bhugra, D. (2012). The portrayal of autism in Hollywood films. International Journal of Culture and Mental Health, 5(1), 54-62.

Crawford, D., \& Godbey, G. (1987). Reconceptualising barriers to family leisure. Leisure Sciences, 9(2), 119-127.

Create London. (2018). Panic! What happened to social mobility in the arts? http://www.createlondon.org/panic/ (accessed 12 May 2020).

Cultural Minister's Council. (2009). Canberra: Council of Australian Governments.

DADAA Inc. (2014). An evaluation of a year-long mentoring program for artists with disability in western Australia. Perth, Western Australia: Department of Family and Community Services.

Dalton, V. (2020). The challenge of engaging with and reporting against the SDGs for SMEs such as Sydney Theatre Company. Journal of Management and Organization, 26(6), 975-994.

Darcy, S., Maxwell, H., Grabowski, S., \& Onyx, J. (2019). Artistic impact: From casual and serious leisure to professional career development in disability arts. Leisure Sciences, 1-20. https://doi.org/10.1080/01490400.2019.1613461.

Egan, L. A., Butcher, J., \& Ralph, K. (2008). Hope as a basis for understanding the benefits and possibilities of community engagement. Victoria, Australia: Institute for Advancing Community Engagement, ACU National.

Evans, T., Bellon, M., \& Matthews, B. (2017). Leisure as a human right: An exploration of people with disabilities' perceptions of leisure, arts and recreation participation through Australian community access services. Annals of Leisure Research, 20 (3), 331-348.

Fujimoto, Y., Rentschler, R., Le, H., Edwards, D., \& Härtel, C. E. J. (2014). Lessons learned from community organisations: Inclusion of people with disabilities and others. British Journal of Management, 25(3), 518-537.

Gidley, J. M., Hampson, G. P., \& Wheeler, L. (2010). Social inclusion: Context, theory and practice. The Australasian Journal of University-Community Engagement, 5(1), 6-36.

Glesne, C., \& Peshkin, A. (1992). Becoming qualitative researchers: An introduction. White Plains, NY: Longman.

Gooding, P., Anderson, J., \& McVilly, K. (2017). Disability and social inclusion 'down under': A systematic literature review. Journal of Social Inclusion, 8(2), 4-25.

Hayes, A., Gray, M., \& Edwards, B. (2008). Social inclusion: Origins, concepts and key themes. ACT, Canberra: Social Inclusion Unit, Department of the Prime Minister and Cabinet.

Hutchinson, M. (2005). Making the journey: Arts and disability in Australia. Sydney: Arts Access Australia.

Kawashima, N. (2006). Audience development and social inclusion in Britain. International Journal of Cultural Policy, 12(1), $55-72$.

Kuppers, P. (2005). Disability and contemporary performance: Bodies on the edge. Oxon: Routledge.

Kusayama, K. (2005). Access to museums for visually challenged people in Japan. International Congress Series, 1282, 877-880.

Lindelof, A. M. (2015). Audience development and its blind spot: A quest for pleasure and play in the discussion of performing arts institutions. International Journal of Cultural Policy, 21(2), 200-218.

Malt, C. (2005). Women's voices in Middle East museums: Case studies in Jordan. Syracuse: University Press.

McGrath, C., Palmgren, P. J., \& Liljedahl, M. (2019). Twelve tips for conducting qualitative research interviews. Medical Teacher, 41(9), 1002-1006.

Merriam, S. B. (1990). Case study research in education: A qualitative approach. San Francisco: Jossey-Bass.

Naraine, M. D., \& Lindsay, P. H. (2011). Social inclusion of employees who are blind or low vision. Disability \& Society, 26(4), 389-403.

Oliver, M. (1990). The politics of disablement: Critical texts in social work and the welfare state. London: MacMillan. 
Oliver, M. (2004). The social model in action: If I had a hammer. In C. Barnes \& G. Mercer (Eds.), Implementing the social model of disability: Theory and research (pp. 18-31). Leeds: The Disability Press.

Park, J., et al.Faulkner, J., \& Schaller, M. (2003). (2003). Evolved disease-avoidance processes and contemporary anti-social behaviour: Prejudicial attitudes and avoidance of people with physical disabilities. Journal of Nonverbal Behaviour, 27(2), 65-87.

Putnam, R. (2000). Bowling alone: The collapse and revival of American community. New York: Simon \& Schuster.

Rankin, S. (2018). Cultural justice and the right to thrive. Platform Paper No. 57, Sydney: Currency House.

Rentschler, R., \& Hede, A. (2007). Museum marketing: Competing in the global marketplace. Oxford, England: Butterworth-Heinemann.

Rentschler, R., Lee, B., Yoon, J, \& Collins, A. (in press). 'I am a professional dancer': A case study of performing artists with disability. In M. J. Wyszomirski \& W. Chang (Eds.), Building professionalism in the creative sector. Oxon: Routledge.

Report on the World Social Situation (2016). Leaving no one behind: The imperative of inclusive development. New York: United Nations Department of Economic and Social Affairs.

Richardson, N. (2016). Transgressive bodies: Representations in film and popular culture. Burlington, VT: Ashgate.

Rosqvist, H. B., Chown, N. and Stenning, A. (Eds.) (2020). Neurodiversity studies: A new critical paradigm. New York: Routledge.

Ruiz, B., Pajares, J. L., Utray, F., \& Moreno, L. (2011). Design for all in multimedia guides for museums. Computers in Human Behavior, 27(4), 1408-1415.

Ryan, C., \& Collins, A. B. (2008). Entertaining international visitors: The hybrid nature of tourism shows. Tourism Recreation Research, 33(2), 143-149.

Sadler, G. R., Lee, H. C., Lim, R. S. H., \& Fullerton, J. (2010). Recruitment of hard-to-reach population subgroups via adaptations of the snowball sampling strategy. Nursing \& Health Sciences, 12(3), 369-374.

Sandell, R. (1998). Museums as agents of social inclusion. Museum Management and Curatorship, 17(1), 401-418.

Sandell, R. (2003). Social inclusion, the museum and the dynamics of sectoral change. Museum \& Society, 1(1), 45-62.

Scheerenberger, R. (1983). A history of mental retardation: A quarter century of progress. Baltimore, MD: Brookes.

Schoultz, J., Säljö, R., \& Wyndhamn, J. (2001). Heavenly talk: Discourse, artifacts, and children's understanding of elementary astronomy. Human Development, 44(2-3), 103-118.

Sen, A. (1985). Well-being, agency and freedom: The Dewey lectures 1984. The Journal of Philosophy, 82(4), 169-221.

Shakespeare, T. (2006). The social model of disability. In L. J. Davis (Ed.), The disability studies reader (2nd ed., pp. 197-204). New York, NY: Routledge.

Sharma, P., \& Varma, S. K. (2008). Women empowerment through entrepreneurial activities of self help groups. Indian Research Journal Extension Education, 8(1), 46-51.

Solvang, P. K. (2018). Between art therapy and disability aesthetics: A sociological approach for understanding the intersection between art practice and disability discourse. Disability \& Society, 33(2), 238-253.

Stake, R. E. (1995). The art of case study research. Thousand Oaks, CA: Sage.

Syed, J., \& Kramar, R. (2009). Socially responsible diversity management. Journal of Management and Organizations, 15, 639-651.

Taylor, S., \& Bogdan, R. (1989). On accepting relationships between people with mental retardation and non-disabled people: Towards an understanding of acceptance. Disability, Handicap \& Society, 4(1), 21-36.

Themudo, N. S. (2009). Gender and the nonprofit sector. Nonprofit and Voluntary Sector Quarterly, 38(4), 663-683.

Thomas, C. (2004). Developing the social relational in the social model of disability: A theoretical agenda. In C. Barnes \& G. Mercer (Eds.), Implementing the social model of disability: Theory and research (pp. 32-47). Leeds: The Disability Press.

Thomas, Y., Gray, M., McGinty, S., \& Ebringer, S. (2011). Homeless adults engagement in art: First steps towards identity, recovery and social inclusion. Australian Occupational Therapy Journal, 58(6), 429-436.

Verhaeghe, P.-P., Van der Bracht, K., \& Van de Putte, B. (2016). Discrimination of tenants with a visual impairment on the housing market: Empirical evidence from correspondence tests. Disability and Health Journal, 9(2), 234-238. https://doi. org/10.1016/j.dhjo.2015.10.002.

vom Lehn, D. (2010). Discovering 'experience-ables': Socially including visually impaired people in art museums. Journal of Marketing Management, 26(7-8), 749-769.

Walmsley, B. (2016). From arts marketing to audience enrichment: How digital engagement can deepen and democratize artistic exchange with audiences. Poetics, 58, 66-78.

Wiesel, I., \& Bigby, C. (2016). Mainstream, inclusionary, and convivial places: Locating encounters between people with and without intellectual disabilities. Geographical Review, 106(2), 201-214.

Williams, K., \& Murray, D. (2015). Negotiating the normative: The other normal for mothers of disabled children. Journal of Family Studies, 21(3), 324-40.

Woods, R. (2017). Exploring how the social model of disability can be re-invigorated for autism: In response to Jonathan Levitt. Disability \& Society, 32(7), 1090-1095.

Zimmerman, M. A. (2000). Empowerment theory handbook of community psychology. Boston: Springer. 
Dr. Ayse Collins is an Associate Professor in the Department of Tourism and Hotel Management, Bilkent University, Ankara, Turkey. She obtained her PhD from Middle East Technical University, Ankara, Turkey, where her thesis won the 'Thesis of the Year' award. Her research interests cover human resources management, labour law, curriculum development, performance evaluation, inclusion, social inclusion, disability and arts. She is the member of editorial boards of several international and national journals.

Dr. Ruth Rentschler OAM is Professor Arts \& Cultural Leadership and Head, School of Management, University of South Australia. She has published widely on matters related to the diversity and the arts in journal articles, industry reports, books and conference papers. She has a strong service record both in universities and in the community, serving on non-profit boards, editorial boards and as conference and doctoral symposium organiser.

Dr. Karen Williams is a lecturer in the School of Management at the UniSA Business School. Karen's teaching and research lie in sociology, gender, disability, representation and inclusion and sport and leisure.

Dr. Fara Azmat is an Associate Professor in the Department of Management at Deakin University, Melbourne, Australia. Her areas of research interest are: social responsibility of small businesses, corporate social responsibility in developing countries, women entrepreneurship, poverty and sustainable development. She is currently serving as a member of the Editorial board of Social Responsibility Journal, a fellow and member of the Economic and Social Research Council (ESRC), Peer Review College UK.

Cite this article: Collins A, Rentschler R, Williams K, Azmat F (2021). Exploring barriers to social inclusion for disabled people: perspectives from the performing arts. Journal of Management \& Organization 1-21. https://doi.org/10.1017/ jmo. 2021.48 